\title{
Diagnóstico etiológico de la sordera infantil: Recomendaciones CODEPEH 2015
}

\section{Etiological diagnosis of child deafness: 2015 CODEPEH Recommendations}

\section{Palabras clave:}

Sordera, diagnóstico, etiología, genética, hipoacusia, Atención Temprana.

\section{Keywords:}

Deafness, diagnosis, etiology, genetics, hearing loss, Early Intervention.
Nota del editor: Este artículo ha sido publicado en Núñez, F. et al. (20I 5): "Diagnóstico etiológico de la sordera infantil: Recomendaciones CODEPEH 20I 5 ", Revista FIAPAS, octubrediciembre $2015, \mathrm{n}^{\circ} \mathrm{I} 55$, Separata.

\section{Introducción}

El presente documento de Recomendaciones CODEPEH 2015 ha sido elaborado en el marco del proyecto para favorecer el Diagnóstico Etiológico de la Sordera Infantil, orientado a la Atención Temprana, coorganizado entre el Real Patronato sobre Discapacidad y la Confederación Española de Familias de Personas Sordas-FIAPAS, en colaboración con la Comisión para la Detección Precoz de la Sordera Infantil-CODEPEH.

La importancia del diagnóstico precoz de la hipoacusia es un hecho reconocido, tanto de forma científica como empírica, desde hace décadas.

Hoy en día, muchos países han instaurado programas de cribado neonatal universal de la hipoacusia conforme a las recomendaciones del Joint Committee on Infant Hearing (Joint Committee on Infant Hearing, 2007), que establece la conveniencia de que la detección no se demore más allá del primer mes de vida y que se pueda disponer de la confirmación diagnóstica en el tercer mes para asegurar que los niños reciban el tratamiento adecuado antes de los seis meses, dado que el principal objetivo es lograr la adquisición del

\section{Faustino Núñez Batalla}

<fnunezb@uniovi.es>

Presidente de la CODEPEH. Servicio ORL, Hospital Universitario Central de Asturias-Oviedo. Sociedad Española de Otorrinolaringología

\section{Carmen Jáudenes \\ Casaubón}

<direccion@fiapas.es>

Vocal de la CODEPEH. Directora de la Confederación Española de Familias de Personas Sordas (FIAPAS)

\section{José Miguel Sequí Canet}

Vocal de la CODEPEH. Jefe de Servicio de Pediatría, Hospital de Gandía-Valencia. Asociación Española de Pediatría

\section{Ana Vivanco Allende}

Vocal de la CODEPEH. Servicio de Pediatría, Hospital Universitario Central de Asturias-Oviedo.

Asociación Española de Pediatría

\section{José Zubicaray Ugarteche}

Vocal de la CODEPEH. Servicio ORL Infantil, Complejo Hospitalario de Navarra-Pamplona. Sociedad Española de Otorrinolaringología

\section{Ruben Cabanillas Farpón}

Director Médico. Instituto de Medicina Oncológica y Molecular de Asturias (IMOMA)

Para citar:

Núñez, F. et al. (20I6): "Diagnóstico etiológico de la sordera infantil: Recomendaciones CODEPEH 201 5 ", Revista Española de Discapacidad, 4 (I): I93-2I8.

Doi: <http://dx.doi.org/IO.5569/23405IO4.04.OI.II> 
lenguaje hablado y el máximo desarrollo de los niños con un déficit auditivo a todos los niveles: personal, cognitivo, educativo y social. Dentro de este proceso, la necesidad de contar con un protocolo de diagnóstico etiológico ha pasado a ser uno de los principales focos de interés de los profesionales implicados.

El límite entre las hipoacusias de causa genética y las de causa ambiental no está claramente definido. Pese a que se calcula que el $60 \%$ de las sorderas de inicio precoz son de causa genética y el $40 \%$ de causa ambiental, la presencia de una de estas últimas causas no excluye la existencia de una predisposición genética (Kochhar et al., 2007) (Cabanillas y Cadiñanos, 20I2). En un estudio llevado a cabo en neonatos con hipoacusia confirmada (Declau et al., 2008), se encontró un factor etiológico en casi la mitad de los casos y, de éstos, correspondían a causas genéticas más del $60 \%$, a problemas perinatales un $20,8 \%$ y a infección congénita por citomegalovirus un I $8,8 \%$.

La identificación de la causa de la hipoacusia de forma precoz tiene numerosas ventajas: evita costosas e innecesarias pruebas, reduce el estrés de los padres y del niño, permite ofrecer consejo genético, si procede, y nos proporciona información acerca del pronóstico, pudiendo identificar e incluso anticipar potenciales problemas médicos coexistentes. Todo ello también sirve de guía para una actuación terapéutica exitosa.

En este momento, frente a la práctica de llevar a cabo extensas baterías de costosas pruebas de forma simultánea en todo niño con hipoacusia, se hace necesario establecer un algoritmo que guíe al profesional para llegar a un diagnóstico etiológico de forma eficiente, teniendo presente en todo caso que debe llevarse a cabo de manera que no entorpezca ni retrase la intervención temprana.

Por ello, la CODEPEH considera necesario formular unas recomendaciones sobre la materia, habida cuenta los importantes avances en el campo de la genética molecular, fundamentalmente, así como en el diagnóstico por imagen.
Estas recomendaciones se basan en la más reciente evidencia científica y pretenden poner orden en un proceso para el que no se dispone de protocolos consensuados, lo que da lugar a casos que se quedan sin diagnóstico, o bien, a la realización indiscriminada de numerosas pruebas, causando molestias innecesarias a los niños y a sus padres, además de originar un gasto sanitario injustificado.

En definitiva, con este nuevo documento de Recomendaciones 20I 5, la CODEPEH pretende ofrecer unas orientaciones de apoyo al profesional en la toma de decisiones durante el proceso de diagnóstico etiológico, dirigidas también a evitar, en la medida de lo posible, la variabilidad en la actuación clínica que se ha observado y documentado en otros países (Rangan et al., 20I2).

\section{Secuencia diagnóstica}

La correcta orientación etiológica requiere la recogida exhaustiva de los antecedentes familiares y personales, incluyendo los factores de riesgo y una detallada exploración física, así como la realización, cuando sea preciso y en relación con estos apartados, de los estudios complementarios pertinentes.

\subsection{Anamnesis y exploración física}

\subsubsection{Antecedentes familiares}

Para la recogida de datos acerca de los antecedentes familiares del caso índice, sería idóneo poder determinar el árbol genealógico, teniendo en cuenta que se deben cumplir varias premisas para que éste tenga validez (Alford $e t$ al., 20I4):

- Intentar recoger datos de tres generaciones, con especial hincapié en los familiares de primer grado (de los que conviene recoger 
las exploraciones otológicas y audiológicas realizadas).

- Tener en cuenta factores como el dinamismo de los árboles genealógicos de cara a la reevaluación periódica de los mismos, así como las falsas paternidades, las adopciones, las técnicas de reproducción asistida (donación óvulo/espermatozoides) y/o la aparición de mutaciones de novo.

- Recoger datos acerca del patrón de herencia, consanguinidad, etnia y país de origen.

\subsubsection{Antecedentes personales y factores de riesgo}

Dentro de la historia clínica se deben recoger datos acerca de la salud tanto de la madre, como del padre. Debe incluirse información sobre el embarazo, el parto y el período neonatal.

\section{Historia perinatal y postnatal}

Conviene insistir en la recogida de datos acerca del embarazo en lo relativo a exposición a medicaciones, drogas y/o tóxicos (Dyer et al., I998) (Takemori et al., I976).

No hay que olvidar tampoco que una de las causas más frecuentes de sordera son las infecciones pre y perinatales (Tabla I), cuyo diagnóstico puede hacerse en la madre, en el feto y en el recién nacido.

\begin{tabular}{|c|c|c|c|c|c|c|c|}
\hline $\begin{array}{c}\text { Virus infección } \\
\text { congénita }\end{array}$ & Tipo sordera & Lateralidad & Grado & Incidencia & Prevención & Tratamiento & Recuperación \\
\hline Citomegalovirus & Neurosensorial & Bilateral & Grave & $\begin{array}{c}6-23 \% \\
\text { asintomáticos } \\
22-65 \% \\
\text { sintomáticos }\end{array}$ & No & $\begin{array}{c}\text { Val/ } \\
\text { ganciclovir }\end{array}$ & $\begin{array}{c}\text { Con } \\
\text { tratamiento }\end{array}$ \\
\hline Coriomeningitis & Neurosensorial & Bilateral & Grave & $7,4 \%$ & Aislamiento & $\begin{array}{c}\text { Rivarina } \\
\text { Favipiravir }\end{array}$ & No \\
\hline Rubéola & Neurosensorial & Bilateral & $\begin{array}{c}\text { Moderada- } \\
\text { Grave }\end{array}$ & $12-19 \%$ & Vacuna & No & No \\
\hline VIH & $\begin{array}{c}\text { Neurosensorial } \\
\text { Conductiva }\end{array}$ & $\begin{array}{l}\text { Bilateral } \\
\text { Unilateral }\end{array}$ & $\begin{array}{l}\text { Moderada- } \\
\text { Grave }\end{array}$ & $27,5-33,5 \%$ & $\begin{array}{c}\text { Tratamiento } \\
\text { postexposición }\end{array}$ & $\begin{array}{c}\text { Tratamiento } \\
\text { VIH }\end{array}$ & Variable \\
\hline Herpes Simple & Neurosensorial & $\begin{array}{l}\text { Bilateral } \\
\text { Unilateral }\end{array}$ & $\begin{array}{c}\text { Moderada- } \\
\text { Grave }\end{array}$ & $<33 \%$ & No & Aciclovir & No \\
\hline $\begin{array}{l}\text { Infección } \\
\text { adquirida }\end{array}$ & Tipo sordera & Lateralidad & Grado & Incidencia & Prevención & Tratamiento & Recuperación \\
\hline Sarampión & Neurosensorial & Bilateral & Grave & $0,1-3,4 \%$ & Vacuna, lg & No & No \\
\hline Varicela_zoster & Neurosensorial & Unilateral & $\begin{array}{c}\text { Leve- } \\
\text { Moderada }\end{array}$ & $7-85 \%$ & Vacuna & Aciclovir & Variable \\
\hline Parotiditis & Neurosensorial & Unilateral & Variable & $<4 \%$ & Vacuna & No & Sí \\
\hline Virus del Nilo & Neurosensorial & Bilateral & $\begin{array}{l}\text { Moderada- } \\
\text { Grave }\end{array}$ & Muy rara & Vacuna & No & Sí \\
\hline
\end{tabular}

Fuente: Modificada de Cohen et al., (20I4): "Viral causes of hearing loss: a review for hearing health professionals". Trends in Hearing, 29 (I8): I-I7 
Entre las infecciones pre y perinatales hay algunas, que se detallan a continuación, en las que se realiza estudio y seguimiento durante el embarazo, lo que hace más fácil su sospecha al nacer y su diagnóstico precoz (Badia et al., 20I4):

- Toxoplasmosis: la infección es asintomática en la mayoría de gestantes. El diagnóstico definitivo de infección materna es la demostración de seroconversión de la inmunoglobulina (Ig) G durante la gestación. Para el diagnóstico de infección fetal, se determina la Reacción en Cadena de la Polimerasa (PCR) del germen sospechado en líquido amniótico.

- Sífilis: el diagnóstico es serológico, mediante pruebas no-treponémicas y treponémicas. Para el diagnóstico prenatal de infección congénita es posible detectar el Treponema pallidum en líquido amniótico.

- Rubéola: el diagnóstico de la infección materna consiste en comprobar un aumento del título de inmunoglobulina G (IgG) cuatro veces sobre su valor inicial, también la existencia de inmunoglobulina M (IgM) específica para rubéola, o bien, a través de la identificación del virus en orina o en secreciones nasofaríngeas mediante PCR. El cultivo del virus presenta una baja sensibilidad. El diagnóstico prenatal se realiza mediante detección de IgM en sangre fetal (obtenida después de la semana 22), detección directa del virus en vellosidades coriónicas o PCR en líquido amniótico.

- VIH: se puede hacer la detección mediante técnicas rápidas, como quimioluminiscencia para detectar el antígeno-anticuerpo del VIH I-2, y se confirman los positivos o dudosos con Western Blot en el neonato. En caso de resultado positivo se debe cuantificar el virus por PCR en sangre.

Hay otras infecciones pre-perinatales con una alta incidencia de sordera sobre las que no se hace cribado sistemático y, por lo tanto, su sospecha depende de la clínica que presente el feto o el neonato. Es el caso de los siguientes virus:
- Citomegalovirus (CMV): este virus actualmente es la causa más frecuente de infección congénita y una de las causas de sordera que, en ocasiones, es postnatal y progresiva. El CMV llega a ser la causa de la sordera en un 10-20\% de niños con hipoacusia comprobada, aunque en algunos estudios esta cifra alcanza el 30\% (Park et al., 20I4).

La mayoría de los neonatos son asintomáticos al nacer. Aproximadamente un IO-I $5 \%$ de neonatos asintomáticos desarrollarán sordera. Algunos de éstos tendrán resultados alterados en el proceso de cribado auditivo neonatal. En varios estudios fueron identificados hasta un $75 \%$ de niños con infección congénita gracias a las alteraciones en el proceso de cribado auditivo. Un $9 \%$ presentaron sordera de inicio posterior (no son, por tanto, tributarios de diagnóstico dentro de un programa de cribado neonatal), siendo ésta progresiva en el $20 \%$ de casos a lo largo de la infancia (DemmlerHarrison, 201 5: en línea) (Goderis et al., 20I4).

En los casos sintomáticos, entre un 30-50\% tendrán sordera que puede ser detectada al nacer, pero en un I 8-30\% se presentará posteriormente, pudiendo ser progresiva hasta en el $63 \%$ de los casos, a lo largo de los primeros 6 años de vida, y llegando a ser profunda en el $78 \%$ de ellos.

El riesgo de transmisión vertical es mucho mayor en la primoinfección que en las infecciones recurrentes ( $32 \%$ vs. I, $4 \%$ ), al igual que la gravedad de los síntomas.

El estudio del CMV está indicado en lactantes con pérdida auditiva comprobada. Se debe valorar, asimismo, su realización en aquellos casos asintomáticos que presentan resultados finales alterados en el proceso de cribado auditivo neonatal y son remitidos al otorrinolaringólogo (ORL) para confirmación.

El plazo límite para diagnosticar la infección congénita con seguridad son las 2-3 semanas de vida postnatal. Dentro 
de ese plazo, lo indicado es hacer una PCR del germen en orina, saliva o sangre. Si el neonato tiene más de 2-3 semanas de vida, esta PCR no será determinante, por lo que se debe recurrir entonces a la PCR en el papel secante de la prueba de metabolopatías para poder confirmarlo (Botet et al., 201 5 ) (Escosa-García et al., 201 5 ) (Escosa-García et al., 20 I 5 ) (Ross et al., 20I 5 ) (Cardoso et al., 20I 5 ) (Boppana et al., 2010) (Koontz et al., 20I 5 ).

- Virus Herpes: el diagnóstico se realiza a través de cultivo viral y determinación de PCR de las vesículas, conjuntiva, orofaringe, sangre y líquido cefalorraquídeo (LCR). La serología tiene escaso valor, aunque la persistencia de IgG durante más de 6-I 2 meses confirma la infección neonatal. Según algunos estudios, el herpes también puede ocasionar sordera de la misma forma que el CMV, aunque parece ser más infrecuente (Dahle y McCollister, I988).

- Varicela neonatal: el diagnóstico es clínico, pero se recomienda la confirmación serológica, IgG e IgM, con dos muestras, en un intervalo de 15 días. Se puede realizar también la detección de PCR específica en las lesiones cutáneas. Raramente produce sordera.

- Otros gérmenes: conviene recordar que el virus de la parotiditis, el virus del Nilo y muchos otros gérmenes pueden ser causantes de sordera en niños (Cohen et al., 20I4).

Además de lo descrito hasta ahora hay que tener en consideración otros antecedentes de riesgo como: traumatismos craneoencefálicos, exposición a medicamentos ototóxicos y/o quimioterápicos, ingreso en Cuidados Intensivos (ventilación asistida, ventilación con membrana extracorpórea, hiperbilirrubinemia con exanguinotransfusión, gran prematuridad, hipoxia perinatal), otras infecciones perinatales, incluyendo las meningitis bacterianas o víricas, enfermedades neurodegenerativas, anomalías craneofaciales y otitis persistente (Núñez et al., 20I 5 ).

\section{Valoración audiológica}

Valoración y clasificación de la hipoacusia según las Recomendaciones CODEPEH 2010 y 2014 (Trinidad et al., 20IO) (Núñez et al., 20I 5 ).

\section{Alteraciones en otros sistemas}

Además de recoger los antecedentes y factores de riesgo, es necesario también descartar la presencia de alteraciones en otros sistemas como la esfera neurológica, oftalmológica, vestibular, cardiológica u otros; así como datos acerca del desarrollo psicomotor.

\subsubsection{Exploración física}

En relación con la clasificación de la hipoacusia como sindrómica o no sindrómica, existen diversos signos de la exploración física que se deben reconocer dado que pueden orientar hacia algún tipo de síndrome, pues se estima que hasta un $30 \%$ de las hipoacusias de causa genética son sindrómicas (Alford et al., 20I4).

Por tanto, se debe focalizar la exploración física en rasgos dismórficos y otros signos clínicos, como los siguientes (Pickett y Ahlstrom, I999):

\section{Aspecto general (Tabla 2)}

Se debe recoger la talla del paciente, el hábito corporal, la coloración de la piel, el pelo y las lesiones cutáneas, así como la morfología craneofacial.

\section{Orejas (Tabla 3)}

Se debe examinar el tamaño y la morfología del pabellón auricular, así como el lugar de implantación. Es importante también la existencia de fositas o apéndices preauriculares, además de la atresia aural.

\section{Ojos (Tabla 4)}

Es importante destacar en la exploración física la disposición de las hendiduras palpebrales, la 
distancia intercantal, la morfología y color del iris y la córnea, así como la agudeza visual, sin olvidar la musculatura motora ocular.

\section{Boca (Tabla 5)}

La existencia de labio leporino o paladar hendido son aspectos relacionados con la hipoacusia.

\section{Facies (Tabla 6)}

Muchos síndromes cursan con anomalías faciales asociadas a hipoacusia, por lo que se deben recoger datos acerca de la morfología facial, el desarrollo óseo y/o muscular de la cara, así como la morfología nasal.

\section{Cuello y extremidades (Tabla 7)}

Se deben recoger datos acerca de la morfología y longitud del cuello, así como su movilidad y la existencia de masas. Por otro lado, es importante la morfología y tamaño de las extremidades.

\begin{tabular}{l}
\hline Tabla 2. Aspecto general \\
\begin{tabular}{|l|l|c|}
\hline Aspecto físico & Orienta a: & Tipo de Hipoacusia \\
\hline Talla corta & $\begin{array}{l}\text { Mucopolisacaridosis } \\
\text { Acondroplasia }\end{array}$ & Transmisiva \\
\hline Hábito asténico & Sd. de Marfan & Mixta \\
\hline Piel y pelo & $\begin{array}{l}\text { Albinismo } \\
\text { Léntigo: Sd. de Leopard } \\
\text { Manchas café con leche: Sd. von Recklinghausen } \\
\text { Mechón blanco: Sd. Waardenburg }\end{array}$ & Neurosensorial \\
\hline $\begin{array}{l}\text { Morfología craneofacial } \\
\text { anómala }\end{array}$ & $\begin{array}{l}\text { Sd. de Apert } \\
\text { Enfermedad de Crouzon }\end{array}$ & Transmisiva \\
\hline
\end{tabular}
\end{tabular}

Fuente: elaboración propia.

\begin{tabular}{l|l|c|}
\hline Tabla 3. Orejas & Tipo de Hipoacusia \\
\hline Aspecto físico & Orienta a: & Transmisiva \\
\hline Microotia & $\begin{array}{l}\text { Sd. de Treacher-Collins } \\
\text { Sd. de Goldenhar } \\
\text { Sd. de Möbius } \\
\text { Sd. Oto-branquio-renal }\end{array}$ & Transmisiva \\
\hline Implantación baja & $\begin{array}{l}\text { Sd. de Down } \\
\text { Sd. de Apert }\end{array}$ & Transmisiva \\
\hline positas o apéndices & Pueden indicar patología del oído medio & Transmisiva \\
\hline Atresia Aural & $\begin{array}{l}\text { Defecto aislado } \\
\text { Transmisiva Sd. de Treacher-Collins } \\
\text { Sd. de Goldenhar } \\
\text { Sd. de Klippel-Feil }\end{array}$ & \multicolumn{2}{|l}{} \\
\hline
\end{tabular}

Fuente: elaboración propia. 


Tabla 4. Ojos
\begin{tabular}{|l|l|c|}
\hline Alteración ocular & Orienta a: & Tipo de Hipoacusia \\
\hline Hendiduras palpebrales & Sd. de Treacher-Collins & Transmisiva \\
\hline Aumento distancia intercantal y heterocromía de iris & Sd. Waardenburg & Neurosensorial \\
\hline Coloboma & Sd. Charge & Neurosensorial \\
\hline Estrabismo & Sd. de Duane & Transmisiva \\
\hline Parálisis ocular & Sd. de Möbius & Transmisiva \\
\hline Opacificación corneal & Sifilis congénita & Neurosensorial \\
\hline Cataratas & Rubéola congénita & Neurosensorial \\
\hline Pérdida de agudeza visual & $\begin{array}{l}\text { Sd. de Usher } \\
\text { Sd. de Refsum }\end{array}$ & Neurosensorial \\
\hline Ceguera & $\begin{array}{l}\text { Sd. de Stickler } \\
\text { Sd. de Cockayne } \\
\text { Sd. de Marshall }\end{array}$ & Neurosensorial \\
\hline
\end{tabular}

Fuente: elaboración propia.

\section{Tabla 5. Boca}

\begin{tabular}{|l|l|c|}
\hline Alteración & Orienta a: & Tipo de Hipoacusia \\
\hline \multirow{3}{*}{ Labio leporino y paladar hendido } & $\begin{array}{l}\text { Labio leporino o paladar hendido aislado } \\
\text { Sd. Orofaciodigital } \\
\text { Sd. Oropalatodigital } \\
\text { Sd. de Pierre-Robin }\end{array}$ & Transmisiva \\
\hline
\end{tabular}

Fuente: elaboración propia.

\begin{tabular}{l}
\hline Tabla 6. Facies \\
\begin{tabular}{|l|l|c|}
\hline Alteraciones asociadas & Orienta a: & Tipo de Hipoacusia \\
\hline $\begin{array}{l}\text { Óculo-aurículo-vertebral } \\
\text { Desarrollo aberrante de los } 1^{\circ} \text { y } 2^{\circ} \text { arcos branquiales } \\
22 \% \text { disfunción del nervio facial }\end{array}$ & Sd. de Goldenhar & $\begin{array}{c}75 \% \text { Transmisiva } \\
11 \% \text { Neurosensorial }\end{array}$ \\
\hline $\begin{array}{l}\text { Disóstosis mandibulo-facial: mejillas aplanadas, cara } \\
\text { estrecha, hipoplasia mandibular }\end{array}$ & Sd. de Treacher-Collins & Transmisiva \\
\hline Hueso frontal prominente, facies tosca & Sd. de Hurtlen & Transmisiva \\
\hline Protuberancia frontal & Sd. Oto-palato-digital & Transmisiva \\
\hline Micrognatia & $\begin{array}{l}\text { Sd. de Apert } \\
\text { Sd. de Pierre-Robin }\end{array}$ & Transmisiva \\
\hline Anomalías nasales & Sd. de Waarneburg & Neurosensorial \\
\hline Nariz en silla de montar & Sifilis congénita & Neurosensorial \\
\hline Nariz en pico de loro & Sd. de Crouzon & Trasmisiva \\
\hline
\end{tabular}
\end{tabular}

Fuente: elaboración propia. 


\begin{tabular}{|c|c|c|}
\hline Alteraciones asociadas & Orienta a: & Tipo de Hipoacusia \\
\hline $\begin{array}{l}\text { Anomalías de oído externo, medio o interno } \\
\text { Cuello corto y ancho con movilidad reducida }\end{array}$ & Sd. de Klippel-Feil & $\begin{array}{l}\text { Transmisiva } \\
\text { Mixta } \\
\text { Neurosensorial }\end{array}$ \\
\hline Cuello largo y delgado & Sd. de Marfan & $\begin{array}{l}\text { Transmisiva } \\
\text { Mixta } \\
\text { Neurosensorial }\end{array}$ \\
\hline $\begin{array}{l}\text { Masas cervicales anteriores al músculo ECM (quistes } \\
\text { branquiales) }\end{array}$ & Sd. Oto-branquilo-renal & Transmisiva \\
\hline Marca cervical media (bocio) & Sd. de Pendred & Neurosensorial \\
\hline Sindactila & Sd. de Apert & Transmisiva \\
\hline Contracturas en flexión de los dedos & Sd. de Hurler & Neurosensorial \\
\hline Deformidades tipo pinzas de langosta & Sd. de Cockayne & Neurosensorial \\
\hline
\end{tabular}

Fuente: elaboración propia.

\subsection{Pruebas complementarias}

\subsubsection{Pruebas genéticas}

La mayoría de las hipoacusias neurosensoriales congénitas tienen un carácter no sindrómico y una etiología genética (Kochhar et al., 2007) (Vona et al., 20I 5), siendo por lo tanto los test genéticos la prueba diagnóstica que ha demostrado tener un mayor rendimiento (Lin et al., 20II) (Robin et al., 2005).

El diagnóstico etiológico de las hipoacusias genéticas es muy complejo y no existen protocolos estandarizados (Lin et al., 2OII).

Tradicionalmente, el diagnóstico genético se ha cimentado en la secuenciación Sanger, desarrollada en el año I975 y basada en la PCR (Sanger y Coulson, I975). Esta técnica, muy sensible y específica, es la de referencia para analizar uno o pocos genes, pero sus costes y sus tiempos la hacen impracticable para secuenciar simultáneamente decenas de genes (Shearer et al., 20I3). El desarrollo tecnológico experimentado en los últimos años en el campo de la secuenciación genómica ha cambiado radicalmente el diagnóstico genético de las enfermedades hereditarias poligénicas, como es el caso de la hipoacusia.

Este desarrollo, sin precedentes en la historia de la biología molecular, permite hoy en día lo que hace menos de diez años era una utopía: secuenciar tantos genes como se quiera (desde unas decenas, al genoma completo), en tiempos y costes compatibles con la rutina asistencial (Rehm, 20I3).

Este conjunto de tecnologías, denominadas secuenciación genómica de nueva generación (Next Generation Sequencing -NGS-), permite tres aproximaciones para el diagnóstico de las enfermedades hereditarias (Jamuar y Tan, 20I 5) (Atik et al., 20I 5): a) genoma completo (secuenciación de todo el genoma); b) exoma (secuenciación de las regiones del genoma que codifican la información necesaria para la síntesis de proteínas -exones-) y c) panel de genes (secuenciación de un conjunto de genes asociados con una enfermedad concreta).

Actualmente, en la práctica clínica, los paneles de genes se consideran la metodología más adecuada para el diagnóstico genético de las sorderas (Alford et al., 20I4) (Shearer y Smith, 20I 5 ). El rendimiento diagnóstico esperado de estos paneles se sitúa en torno al $50 \%$ (Schrauwen 
et al., 2013) (Shearer et al., 2013). Esta cifra es muy variable, oscilando entre el I $3 \%$ y el roo\%, diferencia condicionada por la metodología empleada y por la población analizada (Gu et al., 20I 5) (Brownstein et al., 20II).

Previsiblemente, en los próximos años, las tasas de diagnóstico se incrementarán conforme se relacionen nuevos genes con el desarrollo de las hipoacusias hereditarias (Atik et al., 201 5 ).

Cuando mediante un panel no es posible llegar a un diagnóstico, y se sigue sospechando una causa genética subyacente, los exomas son la herramienta adecuada para identificar nuevos genes implicados en sorderas (Vona et al., 20I 5) (Cabanillas et al., 20I I). Hoy día, los exomas deben reservarse para investigación pues resultan más costosos que los paneles, son más difíciles de interpretar y los resultados tardan más tiempo en ser procesados (Shearer et al.,
20I3) (Jamuar y Tan, 20I5). Otro inconveniente de los exomas es el hecho de que, como parte del análisis, se pueden detectar variantes en genes implicados en patologías diferentes a la sordera (Ejemplo: enfermedades neurodegenerativas, cardiopatías hereditarias, etc.), generando dificultades a la hora del asesoramiento genético de estos pacientes (Green et al., 2013).

\section{Implicaciones prácticas}

Si los antecedentes, la exploración y los estudios solicitados no permiten concluir que la hipoacusia sea adquirida, o no hay indicios clínicos que permitan sospecharla, se debe buscar la confirmación de la etiología genética. Para ello, es preciso remitir al paciente a una consulta de consejo genético, de acuerdo con el algoritmo de la Figura I (Kochhar et al., 2007) (Robin et al., 2005) (Cabanillas y Cadiñanos, 20I2).

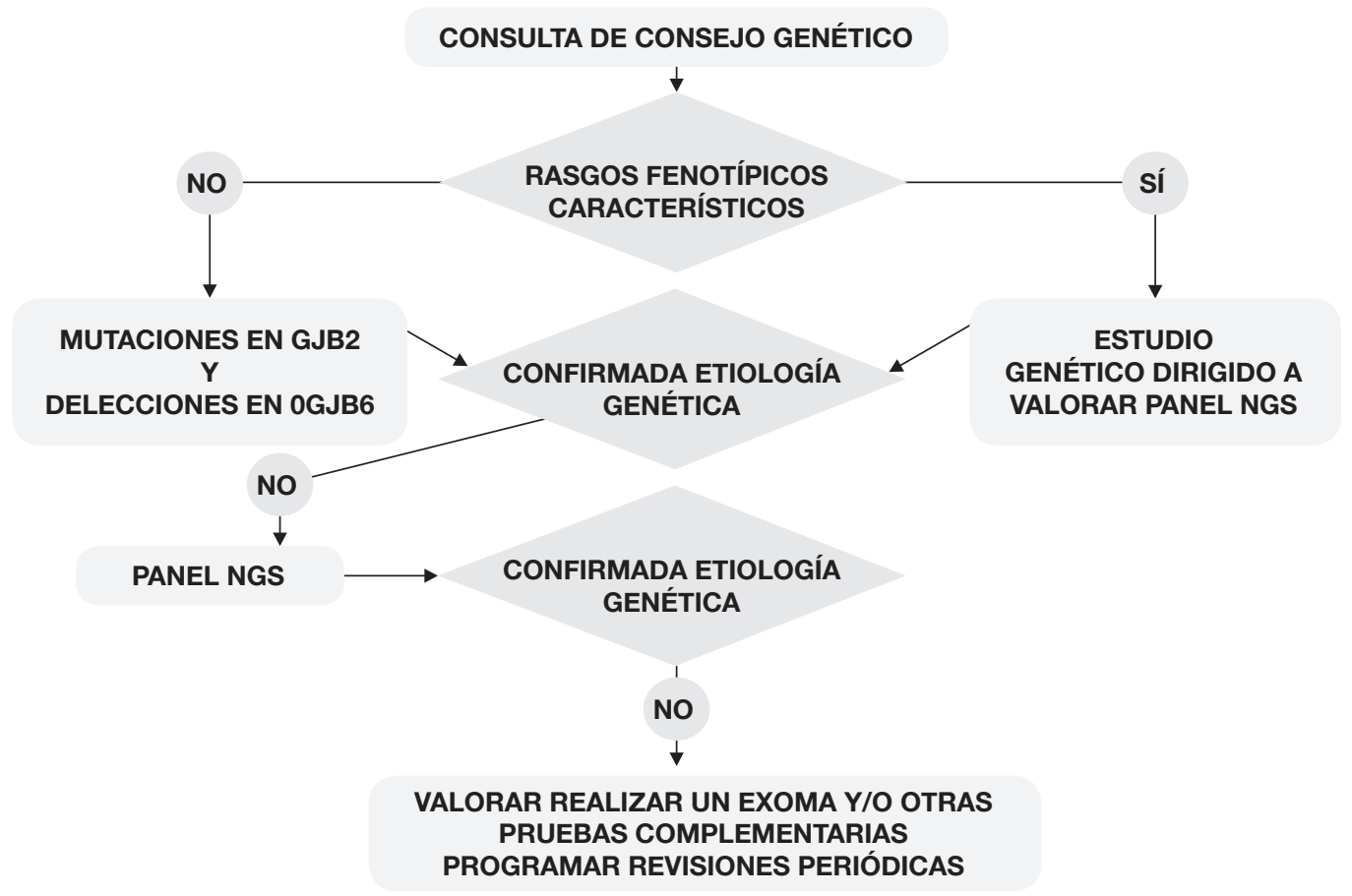

Fuente: elaboración propia. 
En España, la ley establece la necesidad de que exista un proceso de consejo genético antes y después de la realización de cualquier prueba genética, así como la necesidad de un consentimiento informado específico. En esta consulta, que ha de formar parte del equipo multidisciplinar encargado de la atención al paciente con sordera (Cabanillas y Cadiñanos, 20I2), se debe profundizar tanto como sea posible en la caracterización de la hipoacusia. En aquellos casos en los que la evaluación clínica sugiera la posibilidad de que un determinado gen o conjunto de genes pueda ser el responsable del fenotipo, es posible solicitar un estudio genético dirigido (por ejemplo: mutaciones mitocondriales ante un patrón de herencia compatible y antecedentes de ototoxicidad por aminoglucósidos). En ocasiones, cuando se sospecha un síndrome que puede ser ocasionado por varios genes (por ejemplo: síndrome de Usher), puede resultar más rentable, en tiempo y costes, solicitar directamente la secuenciación mediante NGS de un panel, que incluya los genes de interés.

En la mayoría de casos, no será posible identificar un gen candidato a partir del fenotipo. Afortunadamente, en el momento actual el avance en las técnicas de secuenciación, en la interpretación bioinformática y la reducción de costes de los diferentes pasos, hacen posible conseguir un diagnóstico genético, independiente del fenotipo, de forma rápida, sin necesidad de estudios confirmatorios adicionales (Rehm et al., 2013).

En este punto, con la intención de minimizar los costes del proceso, el primer paso recomendado es analizar la presencia de mutaciones en el gen GJB2 y de deleciones en GJB6, dada su elevada prevalencia en nuestro medio (Kenneson et al., 2002) (Schrauwen et al., 2013). Si no es posible identificar la causa de la sordera tras el análisis de estos genes, el siguiente paso debe ser la secuenciación de un panel de genes adecuadamente seleccionado, mediante NGS (Alford et al., 20I4) (Shearer y Smith, 2OI 5). A la hora de seleccionar el panel, se debe prestar atención a los genes incluidos, a su sensibilidad y especificidad, y a su capacidad para detectar variaciones en el número de copias.

Un resultado negativo nunca puede hacer olvidar que éste sólo indica que no se ha detectado una mutación en los genes analizados, pero no excluye la posibilidad de que la causa de la sordera sea genética. Es fundamental que esta información sea transmitida adecuadamente al paciente y/o a sus familiares (por ejemplo, no eliminaría el riesgo de tener nuevos hijos sordos).

Asimismo, en los casos en los que, tras el adecuado proceso diagnóstico, no se ha identificado una causa de la sordera, se debe ofrecer al paciente y a sus familiares participar en proyectos de investigación, destinados a identificar nuevos genes implicados en hipoacusias hereditarias, mediante la secuenciación de su exoma. Igualmente, se deben programar revisiones periódicas (por ejemplo: cada 3 años) con el especialista en consejo genético. De este modo, será posible identificar rasgos sindrómicos de nueva aparición, que puedan no ser evidentes en el momento de la evaluación inicial. Estas revisiones también permiten ofrecer al paciente la posibilidad de realizar nuevos estudios genéticos o de reinterpretar los resultados de los ya realizados, conforme avanza el conocimiento.

\subsubsection{Pruebas de imagen}

En el estudio de la etiología de las hipoacusias neonatales es importante el estudio radiológico por medio de tomografía computerizada (TC) y/o de resonancia magnética (RM) (Lemmerling y De Foer, 2015). Cada una de ellas aporta unas características distintas para el estudio de las diferentes alteraciones anatómicas patológicas en el oído externo, medio e interno, así como en las vías auditivas centrales.

El hueso temporal se desarrolla a partir del primer y segundo arco branquial, dando lugar al oído externo y medio. De la vesícula auditiva se formará el oído interno, lo que significa que las malformaciones de ambos no tienen porqué ocurrir de forma simultánea. Además las 
malformaciones del conducto auditivo interno (CAI) no tienen que relacionarse siempre con malformaciones del oído interno, aunque todas ellas pueden asociarse.
Según la bibliografía, el $39 \%$ de los niños con hipoacusia presenta en la TC algún tipo de malformación visible en el oído, y entre el 2I \% y $33 \%$ en el oído interno (Mafong et al., 2002).

\section{Figura 2. Esquema Diagnóstico por Imagen}

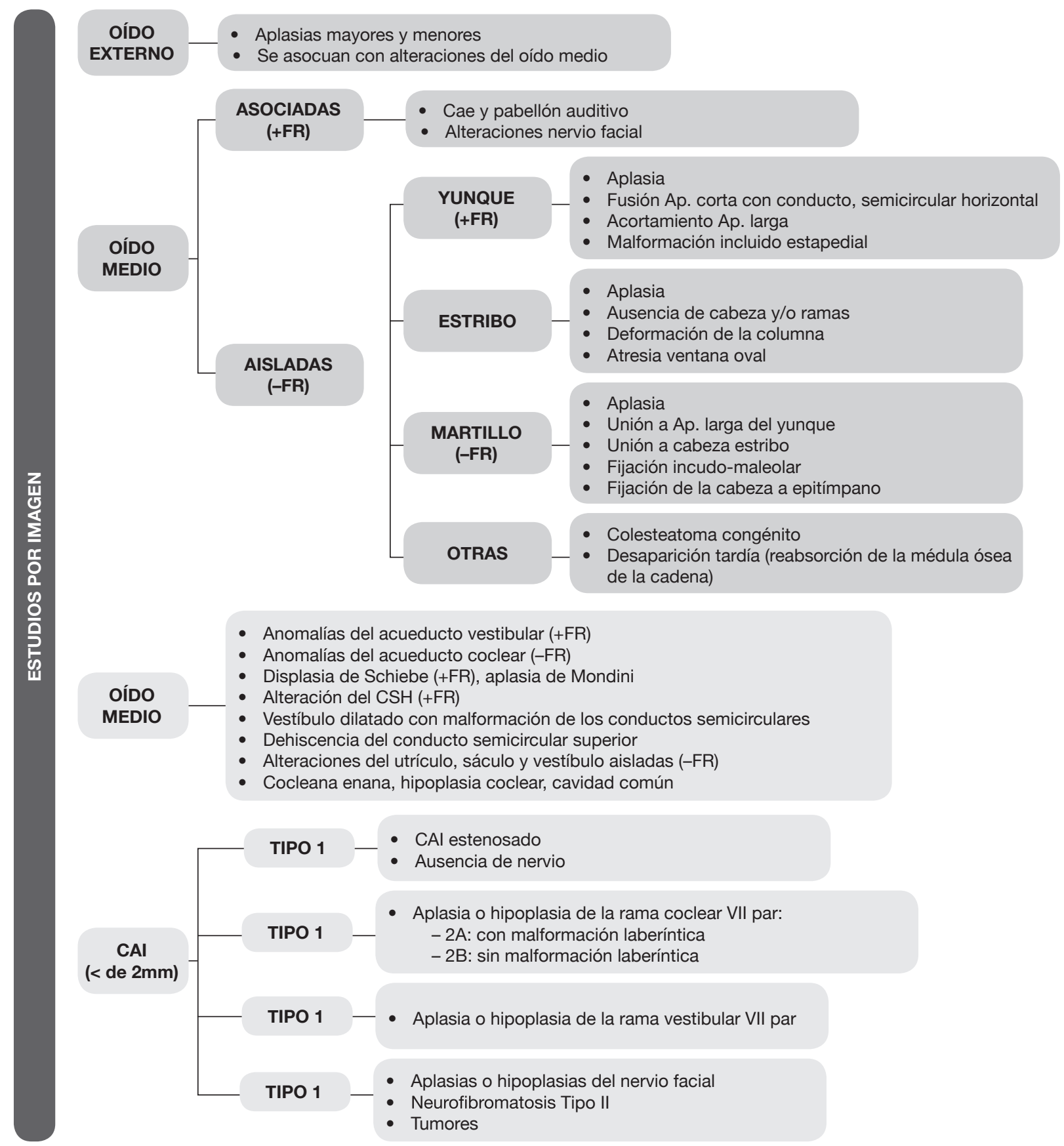

Fuente: elaboración propia. 


\section{Malformaciones (Figura 2)}

- Malformaciones del Oído Externo: tienen una incidencia aproximada entre el $0,7 \mathrm{y}$ el 2,3 por I0.000 nacidos. Frecuentemente son unilaterales y se asocian a diversas malformaciones del oído medio, así como a múltiples síndromes.

- Malformaciones del Oído Medio: las malformaciones aisladas de los huesecillos y las de la estructura de las paredes del oído se asocian, la mayor parte de las veces, a alteraciones del conducto auditivo externo (CAE) como estenosis o atresia y son poco frecuentes de forma aislada.

Los huesecillos que más alteraciones presentan son el yunque y el estribo, siendo menos frecuentes las del martillo.

Existe un cuadro denominado “desaparición tardía”, que ocurre a los 25 meses de edad, momento en el que se produce la trasformación de la medula ósea en hueso.

En este caso, la médula se reabsorbe y da lugar a una gran cavidad medular en el yunque y el martillo. Esto suele ocurrir en el síndrome de Treacher-Collins y la trisomía I3 (Sando et al., I998).

Las alteraciones de la cadena de huesecillos se pueden asociar a alteraciones del nervio facial sobre todo relacionadas con su posición, colocándose con más frecuencia cruzando sobre la ventana oval y fijándose al estribo o junto con agenesia de la ventana oval, aunque puede producirse una atresia aislada.

También se pueden encontrar colesteatomas congénitos.

- Malformaciones del Oído Interno:

- Anomalías del acueducto vestibular.

El acueducto vestibular es una de las últimas estructuras en desarrollarse en el oído interno. Es la causa más frecuente de las malformaciones del oído interno en niños con un 42,9\% de los casos (Deklerck et al., 201 5 ).

Se considera dilatado cuando mide más de I, $5 \mathrm{~mm}$, lo que se produce cuando es mayor que el diámetro de un conducto

\section{Figura 3. Acueducto Vestibular Dilatado}

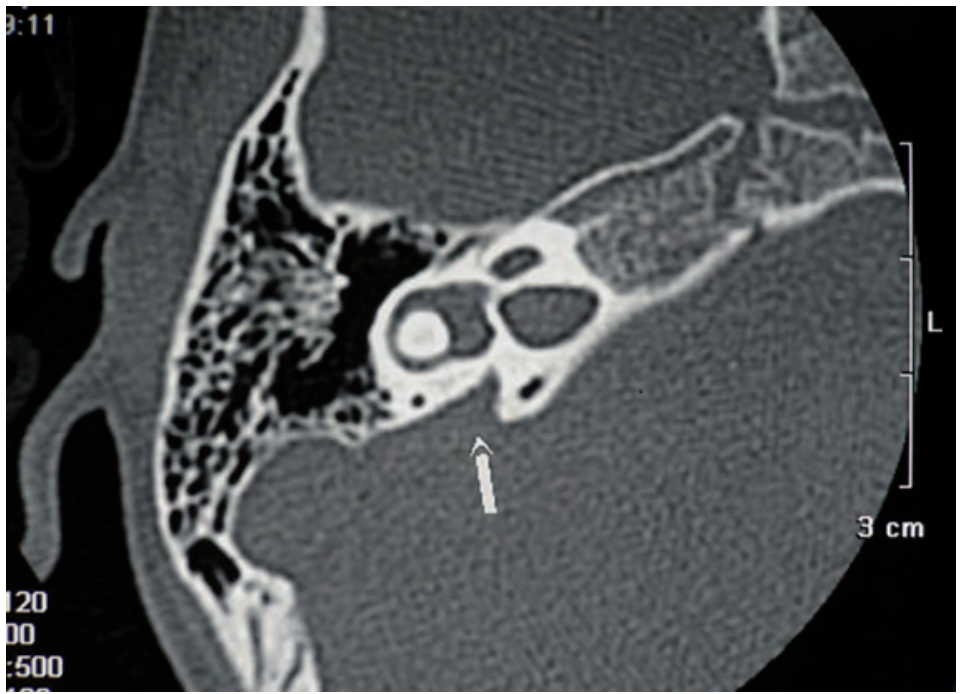

Fuente: elaboración propia. 
semicircular posterior normal (Figura 3). Desde que existen TC de alta resolución se ha demostrado que es muy frecuente que coexista con otras alteraciones cocleares, hasta en el $100 \%$ de los casos según distintas series (Casselman et al., I996).

- Anomalías del acueducto coclear.

Son muy poco frecuentes.

- Anomalías de la cóclea.

Clásicamente se clasificaron como Aplasia de Michel, Aplasia de Bing - Siebenmann, Aplasia de Mondini, Aplasia de Schiebe y Aplasia de Alexander (Valvassori et al., I969). Algunos autores piensan que se pueden reducir a las de Schiebe y Mondini, pero existen numerosas alteraciones que no encajan en ninguna de estas displasias.

La Displasia de Schiebe es la más frecuente de entre las del oído interno, las lesiones se encuentran en el sáculo y cóclea, con atrofia de la estría vascular, deformación de la membrana tectoria y mala diferenciación del órgano de Corti, colapsando la membrana de Reissner.

La alteración de Mondini consiste en la ausencia de desarrollo de una de las espiras, hipoplasia del modiolo y ausencia del tabique interescalar. Se produce por una detención del desarrollo embriológico en la séptima semana de gestación.

- Anomalías del laberinto óseo o membranoso.

La malformación del conducto semicircular horizontal es la alteración más frecuente dentro de este grupo. La de los otros conductos aislados es rara sin asociación con la del conducto semicircular horizontal.

Las malformaciones más severas de los conductos semicirculares se suelen asociar a un vestíbulo dilatado y dan lugar a una cavidad ductal semicircular con el utrículo y el sáculo, absorbiendo uno o todos los conductos semicirculares.
Estas alteraciones pueden ser unilaterales o bilaterales y, en el caso de existir, no siempre dan lugar a hipoacusia, pudiendo producir hipoacusias asimétricas.

También podemos encontrar dehiscencias del conducto semicircular superior.

Lesiones del utrículo, sáculo y vestíbulo aisladas son raras.

En las alteraciones de la cóclea, además de las diferentes clasificaciones, existen otras que no se pueden clasificar, como las cócleas enanas o hipoplásicas con número normal de vueltas. Puede existir una aplasia completa, una cavidad común o una hipoplasia asociada o no a alteraciones semicirculares.

- Anomalías del conducto auditivo interno.

Se considera como patológico un calibre del CAI menor de $2 \mathrm{~mm}$, pudiendo estar estenótico, atrésico o dividido por tabiques óseos. Las alteraciones del CAI también pueden asociarse con aplasias, hipoplasias o duplicaciones del nervio facial.

Entre las lesiones adquiridas, se pueden encontrar lesiones tumorales como en la neurofibromatosis tipo II.

La aplasia del nervio coclear es la causa más frecuente en la sordera neurosensorial unilateral de los niños, siendo poco frecuentes las lesiones tumorales (Laury et al., 2009) (Bockmühl et al., 200I).

Lesiones centrales solas o asociadas a lesiones del nervio vestíbulo coclear y facial son raras e identificables por RM (Singh et al., 201 5).

\section{- Técnicas}

Disponemos fundamentalmente de dos técnicas de imagen para el estudio de la hipoacusia infantil congénita. Éstas son la TC y la RM, si bien hay que tener en cuenta otras técnicas, como puede ser la tomografía por emisión de positrones (PET), que nos aportan imágenes funcionales que, en determinados casos, 
pueden ser importantes a la hora de tomar decisiones terapéuticas.

La TC se utiliza en la actualidad, fundamentalmente, para el diagnóstico de malformaciones del oído medio y externo. Se dispone de dos tipos:

- Multi-slice CT (MSCT), para la adquisición de imágenes en un solo plano.

- ConeBeam CT (CBCT), que puede obtener datos en ${ }_{3} \mathrm{D}$ y hacer reconstrucciones en cualquier plano. En los últimos años este tipo de TC se ha convertido en el de elección, debido a que el tiempo de exposición es menor, tiene resolución espacial más alta y la radiación a la que se somete al niño es más baja. Como inconveniente, señalar su mayor sensibilidad al movimiento del paciente.

La RM se utiliza para el diagnóstico del oído interno, del ángulo pontocerebeloso y del cerebro, así como para el diagnóstico de colesteatoma del oído medio. No existe consenso para seleccionar el tipo de secuencias para el diagnóstico de las lesiones del hueso temporal.

\subsubsection{Pruebas de laboratorio}

En el estudio etiológico sobre la sordera, y siempre después de una correcta anamnesis y una exploración física completa, se puede utilizar el laboratorio para confirmar o apoyar las hipótesis que surgen del primer acercamiento etiológico.

Además de la búsqueda de los agentes infecciosos ya descrita, hay otras exploraciones analíticas útiles en el diagnóstico de sordera como, por ejemplo:

- En casos sospechosos, se debería hacer determinación de metabolismo tiroideo en niños mayores relacionado con el síndrome de Pendred.

- No hay que olvidar comprobar (si constan en la historia) los niveles de medicamentos ototóxicos (por ejemplo, aminoglucósidos/ vancomicina) en los casos de neonatos tratados con ellos.

- El estudio de la orina en los niños mayores puede ser útil en relación con el Síndrome de Alport.

- Otras determinaciones, como la resistencia a insulina, relacionada con el Síndrome de Wolfram, o el estudio de la función renal y paratiroidea en el síndrome de hipoparatiroidismo y sordera sensorioneural junto con enfermedad renal (Síndrome HDR), entre otras, deberían guiarse por la sospecha clínica.

\subsubsection{Otras pruebas: valoración cardiológica}

Relacionado con el Síndrome QT largo, el Síndrome de Jervell y Lange-Nielsen (JLNS) es una variante autosómica recesiva del Síndrome QT largo familiar (SQTL), caracterizado por una pérdida auditiva neurosensorial bilateral profunda congénita, un intervalo QT largo en el electrocardiograma (ECG) y taquiarritmias ventriculares.

La prevalencia es desconocida y varía en función de la población estudiada ( $1: 200.000-$ I:I.000.000). Prácticamente el 50\% de los pacientes se vuelve sintomático antes de cumplir $\operatorname{los} 3$ años.

La presentación típica del JLNS es un niño sordo con episodios sincopales en periodos de estrés, de ejercicio o de miedo. La sordera es congénita, bilateral, profunda y neurosensorial. El intervalo QT en el JLNS es marcadamente prolongado (>500 ms.) y está asociado a taquiarritmias que pueden causar síncope o muerte súbita. El JLNS está causado por mutaciones homocigotas o heterocigotas compuestas en el gen KCNQI (locus LQTI; I IpI 5.5) o en el gen KCNEI (locus LQT 5; 21q22. I-q22.2), y se hereda de forma autosómica recesiva (Crotti et al., 2008). 


\subsubsection{Valoración oftalmológica}

Un tercio de los niños con hipoacusia presenta alteraciones en la exploración oftalmológica que, además, pueden contribuir al diagnóstico etiológico de la sordera, por lo que esta valoración se debe realizar siempre.

\section{Discusión}

El presente documento propone un protocolo diseñado a modo de guía que ayude y oriente a los profesionales a establecer la causa de la hipoacusia confirmada en niños.

Se propone un abordaje secuencial para el diagnóstico etiológico de la hipoacusia de acuerdo a las causas más prevalentes. En la Figura 4 se observa una pirámide invertida, con distintos bloques donde se ubican las diferentes pruebas diagnósticas. La dimensión de cada bloque representa, por una parte, el rendimiento diagnóstico de la prueba (entendiendo por ello la proporción de resultados relevantes) y, por otra, el volumen de niños que se estudiarían con ese método.

El abordaje comienza por las actuaciones y pruebas de primer nivel diagnóstico: la historia clínica y la exploración física.

Se valora la historia familiar y los factores de riesgo de hipoacusia, para lo que es fundamental una correcta anamnesis, así como la realización de un árbol genealógico detallado, siempre que sea posible, y la exploración física del paciente en busca de señales o estigmas que orienten hacia síndromes. Sin duda, la inclusión de datos sobre la historia perinatal y postnatal (con especial atención a los factores de riesgo de hipoacusia) es imprescindible para alcanzar en este bloque el mayor rendimiento diagnóstico de toda la secuencia de pruebas. El rendimiento esperado es de un 4I \% para la historia familiar, un $65 \%$ para los factores de riesgo de hipoacusia y un 2I \% para la exploración en

\section{Figura 4. Secuencia recomendada por la CODEPEH para el Diagnóstico Etiológico (Niveles de} rentabilidad diagnóstica, ordenados de mayor a menor)

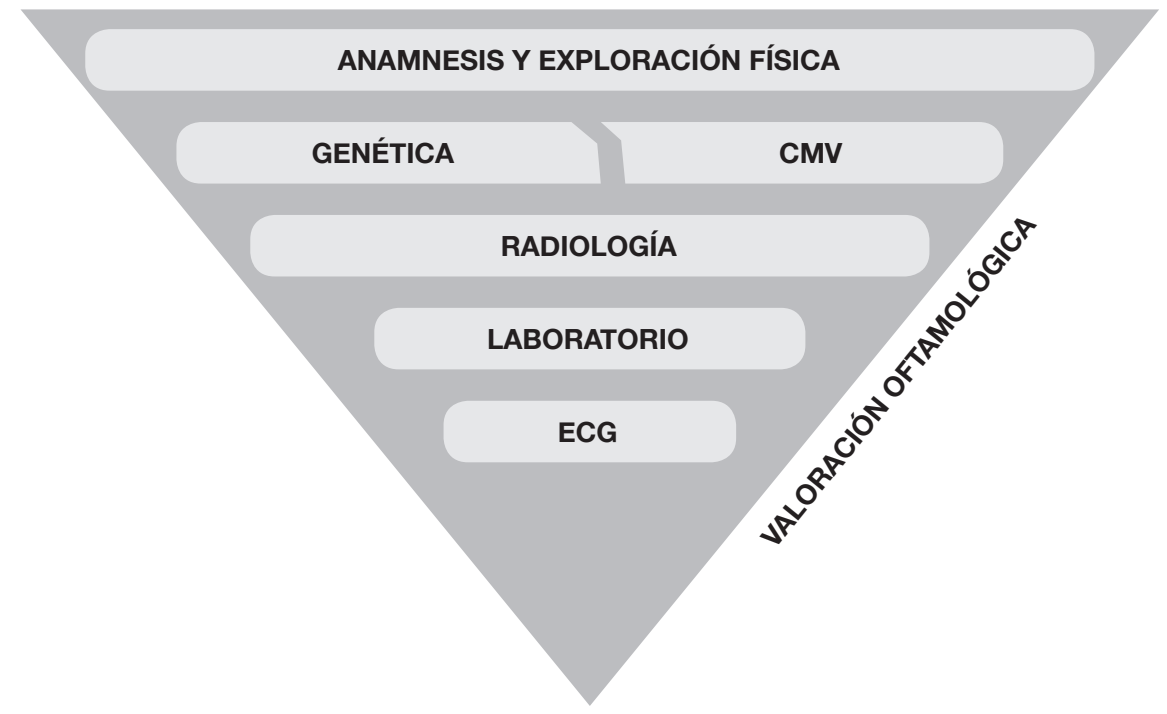

Fuente: elaboración propia. 
busca de anomalías craneofaciales y estigmas de síndromes (Deklerck et al., 2015).

El segundo nivel diagnóstico se corresponde con la realización de pruebas genéticas de distintas modalidades. La extrema heterogeneidad genética de la sordera históricamente ha supuesto una dificultad a la hora de integrar el diagnóstico genético en la práctica clínica. Sin embargo, los beneficios de obtener un diagnóstico etiológico son incuestionables, pues nos proporciona información pronóstica y reproductiva, contribuye a reducir la ansiedad en el paciente y sus familiares, nos permite descartar o prever manifestaciones sindrómicas potencialmente graves, evita la realización de pruebas diagnósticas innecesarias y, en ocasiones, resulta útil en la toma de decisiones terapéuticas (Robin et al., 2005) (Cabanillas y Cadiñanos, 2012) (Palmer et al., 2009).

Este último punto es cada vez más relevante, tanto por la influencia que determinadas alteraciones genéticas pueden tener sobre el rendimiento de los implantes cocleares, como por el hecho de que el diagnóstico genético es el primer paso para poder acceder a futuras intervenciones farmacológicas dirigidas o a eventuales opciones de terapia génica y celular (Muller y Barr-Gillespie, 20I 5 ) (Yu et al., 20I4), opciones que ya han dado sus primeros frutos en cegueras hereditarias (MacLaren et al., 20I4) (Jacobson et al., 20I 5 ).

Se conocen más de 80 genes y más de I.०00 mutaciones diferentes capaces de ocasionar hipoacusia neurosensorial no sindrómica (Shearer y Smith, 20I 5 ).

En nuestro medio, las mutaciones en el gen GJB2 y las deleciones en el gen GJB6 constituyen, en su conjunto, la causa más frecuente de hipoacusia hereditaria (Gallo-Terán et al., 2005) (del Castillo et al., 2005).

Las alteraciones en estos genes justifican entre el ro \% y el $50 \%$ de las sorderas de origen genético, dependiendo este porcentaje de la población objeto del estudio y de las características clínicas de los pacientes evaluados
(Kenneson et al., 2002) (Schrauwen et al., 20I3). Por lo tanto, el análisis de los genes GJB2 y GJB6 es un elemento esencial del proceso diagnóstico de las hipoacusias infantiles (Alford et al., 20I4). El resto de casos son consecuencia de mutaciones en decenas de genes diferentes, responsables cada uno de ellos de un pequeño porcentaje de familias (Schrauwen et al., 20I3) (Vona et al., 20I4). Estos casos serían tributarios de técnicas más amplias como los paneles de genes realizados con estudios de secuenciación de nueva generación (NGS).

Necesariamente, los especialistas que soliciten estudios NGS deben estar familiarizados con las limitaciones de esta tecnología, seleccionando la metodología más adecuada (Jamuar y Tan, 20I 5). Los genes incluidos, la sensibilidad y especificidad del panel, y su capacidad para detectar variaciones en el número de copias son las variables que deben ser tenidas en cuenta a la hora de solicitar y evaluar los resultados de un panel concreto (Shearer y Smith, 20I 5 ) (Rehm et al., 2013).

Conocer los genes que han sido analizados en el panel solicitado resulta crucial para poder comprender el alcance de un test negativo. El diseño de un panel puede incluir desde unas decenas de genes asociados con hipoacusia neurosensorial no sindrómica, a cientos de genes responsables de diferentes síndromes o incluso genes cuya asociación con sordera en humanos sigue siendo objeto de estudio.

En este momento, no existe consenso acerca de cuáles son los genes que deben incluirse en un panel destinado al diagnóstico de una hipoacusia hereditaria, ni los síndromes que deben formar parte del mismo (Shearer y Smith, 20I 5 ). Esto hace que el número de genes de los diferentes paneles oscile desde unas pocas decenas a más de 200.

Sin embargo, existe consenso en que, si se pretende maximizar el rendimiento diagnóstico de los paneles, se deben incluir al menos los síndromes con expresividad variable más frecuentes (Alford et al., 2014) (Behar et al., 20I4) (Lu et al., 20I4). No se debe olvidar que 
aproximadamente el $30 \%$ de las hipoacusias neurosensoriales tienen un carácter sindrómico y, en algunos síndromes, los signos y síntomas no audiológicos pueden ser muy sutiles, especialmente durante los primeros años de vida. Incluso, mutaciones en genes asociados con síndromes como los de Usher, Wolfram, Stickler o Pendred, pueden no tener manifestaciones sindrómicas (Wei et al., 2012) (Young et al., 200I). Más aún, en ocasiones el diagnóstico genético puede ser el único indicio de síndromes potencialmente mortales, como el de Jervell y Lange-Nielsen que, ocasionalmente, puede presentar registros electrocardiográficos de apariencia normal (Tekin et al., 20I4).

Por otro lado, el panel seleccionado debe estar sometido a una revisión continua puesto que cada mes se descubren I ó 2 nuevos genes, cuyas mutaciones pueden ocasionar sorderas perceptivas. De hecho, se han descubierto en los últimos cinco años, mediante la tecnología de NGS, más del $25 \%$ de los genes implicados actualmente en hipoacusias neurosensoriales (Atik et al., 2015).

Es necesario tener en cuenta que existen diferentes metodologías, tanto a la hora de aislar las regiones genómicas que serán analizadas, como para su secuenciación. Mientras que la sensibilidad y la especificad de la secuenciación Sanger es excelente y se considera como patrón de referencia, la de la NGS debe ser contrastada para cada panel, siendo posible alcanzar cifras $>99 \%$. Por lo tanto, el panel seleccionado debe garantizar valores de sensibilidad y especificidad equivalentes a los de la secuenciación (Schrauwen et al., 20I3) (Shearer et al., 2013) (Shearer et al., 2010).

Otra variable que cada vez se revela más importante es la capacidad del análisis para detectar no sólo mutaciones puntuales, sino también variaciones en el número de copias de los genes estudiados. Al menos un I $5 \%$ de las mutaciones capaces de ocasionar hipoacusias son consecuencia de grandes deleciones o amplificaciones, variantes que no son detectadas mediante secuenciación Sanger y que precisan técnicas específicas de NGS para poder ser identificadas (Rehm et al., 2013) (Ji et al., 20I4) (Shearer et al., 20I4).

Ante la ausencia de mutaciones, tras un estudio genético adecuado, hay que valorar la posibilidad de solicitar pruebas complementarias (estudios de imagen, electrocardiograma, evaluación oftalmológica, pruebas vestibulares, estudios microbiológicos y de autoinmunidad, etc.).

En la actualidad, dado el bajo rendimiento diagnóstico de las pruebas complementarias, sus eventuales inconvenientes (dolor, sedación, irradiación, empleo de medios de contraste...) y la eficiencia de los estudios genéticos, debe evaluarse la indicación de pruebas no genéticas en cada caso de forma individual y, salvo que se tenga una sospecha clínica bien definida, deben posponerse hasta que se obtengan los resultados de los estudios genéticos (Lin et al., 20I I) (Alford et al., 20I4) (Madden et al., 2007) (Chiang, 2004).

En este sentido, y en caso de no disponer ya del mismo, se recomienda llevar a cabo, en combinación con las pruebas genéticas, el estudio de la infección por citomegalovirus (CMV), dado que este virus es una de las causas más frecuentes de sordera, a veces postnatal y progresiva, además de no estar incluida su detección en los controles habituales a las gestantes.

Es importante recalcar que la infección por CMV no excluye la posibilidad de presentar de forma simultánea una alteración genética relacionada con la pérdida auditiva, como han demostrado algunos estudios (Karltorp et al., 20I2) (Lim et al., 20I3) (Teek et al., 20I3) (Schimmenti et al., 20I I).

Al igual que en la infección congénita, el diagnóstico de la infección por CMV se basa en el aislamiento del virus o la identificación de su genoma mediante PCR en diversas muestras biológicas (Alarcón y Baquero-Artigao, 20I I) (Badia et al., 20I4) (De Vries et al., 20I3).

La PCR tiene como ventaja la pequeña cantidad de muestra requerida, así como el poco tiempo 
que se necesita para obtener los resultados (entre 24 y 48 horas).

Incluso se han desarrollado métodos de amplificación simple en orina, que tardan sólo una hora en obtener resultados, lo que permite el diagnóstico inmediato del paciente y podría ser muy útil en el estudio de los neonatos que presentan un cribado auditivo alterado, realizado con potenciales automáticos (Kohda et al., 2014).

El diagnóstico de CMV podría tener especial interés en los niños que no superan el cribado neonatal y son remitidos al ORL para confirmación antes de las 2-3 semanas de vida, dado que la mayoría de estudios han concluido que el inicio del tratamiento para el CMV es efectivo si se inicia antes del mes de vida y se prolonga varios meses, al menos entre 6 y I 2 meses (Choi et al., 2009).

Recientemente, se han publicado datos que demuestran que un cribado de CMV en saliva dirigido a neonatos que presentan un proceso de cribado auditivo neonatal alterado es costeefectivo, permitiendo un ahorro de más de un $50 \%$ del gasto (Williams et al., 20I 5 ) (Williams et al., 20I4) (Kadambari et al., 20I3).

Está en discusión la recomendación de realizar cribado universal de la infección por CMV en orina (más exacto) o saliva (más factible) (Kadambari et al., 20I 5 ) (Barkai et al., 2014) (Cannon et al., 20I4) (Botet et al., 20I4), basándose en la elevada prevalencia de la infección y la posibilidad de mejorar el pronóstico con un manejo y tratamiento adecuado (Kimberlin et al., 201 5).

El cribado universal del CMV permitiría captar aquellos neonatos que no son susceptibles de diagnóstico por ser infectados asintomáticos que tienen una primera determinación auditiva normal y pueden presentar sordera posterior (Toumpas et al., 20I4).

A diferencia de la infección congénita por CMV, la infección adquirida en el neonato y lactante no parece asociarse a sordera ni con alteraciones en el neurodesarrollo a largo plazo. De ahí la importancia de la identificación precisa del momento de la infección con la detección por PCR en muestras biológicas de las tres primeras semanas de vida o en la sangre seca de la muestra para metabolopatías, aunque su sensibilidad es menor (aproximadamente del $35 \%$ ) por lo que un resultado positivo confirmaría la infección, pero uno negativo no la descartaría totalmente (Demmler-Harrison, 2015) (Smiechura et al., 20I4) (Núñez-Ramos et al., 20I3). No todos los autores están de acuerdo en la inocuidad de la infección postnatal, por lo que se recomienda seguimiento prolongado de los niños infectados a cualquier edad (Çelikel et al., 20I5).

Aunque se discuta el tratamiento farmacológico, el simple conocimiento de la infección permite el adecuado seguimiento de estos niños y la posibilidad de diagnóstico precoz de la sordera, que permita de forma óptima el tratamiento audiológico más indicado.

Dado que la sordera por CMV se presenta en niños sintomáticos y asintomáticos, siendo fluctuante y con frecuencia postnatal, debe seguirse a estos niños durante al menos 6 años con revisiones más asiduas en los más afectados. Están en desarrollo vacunas para el CMV que podrían variar la situación actual frente a esta enfermedad (Wang y Fu, 20I4) (Schleiss, 20I3).

El tercer nivel diagnóstico corresponde a las pruebas de imagen.

Cada vez es más frecuente hacer exámenes con TC a los niños por diversas causas. Esto incrementa el riesgo de padecer cáncer a lo largo de su vida. Se calcula que el riesgo de padecer un cáncer por una exposición a una TC de cabeza en un niño de un año de edad es del o,07\%. Aunque aparentemente es una cifra baja, se calcula que en los Estados Unidos mueren al año 500 niños por causa de la radiación recibida por TC realizada antes de los I 5 años de edad. (Brenner et al., 200I) (Thomas et al., 2006) (Lee et al., 2004).

Es muy importante tomar conciencia de que, a la hora de realizar un diagnóstico en niños, 
debemos elegir bien la técnica de imagen para evitar efectos secundarios que, aunque sean infrecuentes, pueden producir por esta causa mortalidad en un número de casos nada despreciable (Lee et al., 2004).

Hay que tener en cuenta que muchos de los niños con hipoacusia además tienen asociadas otras patologías que también necesitan estudios radiológicos. En estos casos se debe intentar mejorar la coordinación para que los distintos profesionales que atienden al niño aprovechen ese momento para realizarlos de forma conjunta, sobre todo si se van a realizar en la misma área corporal. Además se debe determinar la prueba que más información vaya a aportar y la TC de mejor calidad para disminuir la radiación y el número de repeticiones por dudas en el diagnóstico.

Conviene insistir en que si se realiza una prueba debe ser para orientar un diagnóstico, un pronóstico y, sobre todo, un tratamiento, por lo que habrá que elegir también la edad adecuada en relación a los objetivos, causando el menor daño al paciente.

Cuanto mayor sea el niño, los riesgos debidos a la radiación serán menores por lo que, para las malformaciones de oído medio y externo, debemos posponer el estudio con TC hasta los 3 ó 4 años de edad, en el mejor de los casos. Y, en las hipoacusias neurosensoriales, comenzar siempre el estudio con una RM.

Tampoco se debe olvidar que los niños pequeños necesitan sedación para la realización de estas pruebas, con los riesgos e incomodidades que ello implica (American Academy of Pediatrics, 2006).

El cuarto nivel diagnóstico lo componen las pruebas de laboratorio y otras exploraciones complementarias.

Entre ellas se incluyen: análisis de laboratorio, dirigidos a confirmar sospechas clínicas y síndromes asociados, así como la realización de electrocardiograma (ECG) en pacientes con arritmias o síncopes.
Además de todo lo descrito, y dada su relevancia, es importante destacar la obligatoriedad de una adecuada y completa exploración oftalmológica en todos los casos, dado que un tercio de niños con hipoacusia presentan alteraciones en esta exploración que, por otra parte, puede orientar hacia la etiología de la sordera.

\section{Recomendaciones CODEPEH 2015}

La secuencia recomendada para el diagnóstico etiológico de la sordera infantil (Figura 4), de acuerdo con los distintos niveles de rentabilidad diagnóstica, de mayor a menor, es la siguiente:

- Primer nivel diagnóstico. Anamnesis y exploración física.

- Realizar un árbol genealógico detallado a través de la historia familiar.

- Recoger datos acerca de factores de riesgo de hipoacusia.

- Tomar en consideración, dentro de la exploración física completa, datos acerca de los estigmas relacionados con hipoacusias sindrómicas.

- Segundo nivel diagnóstico. Pruebas genéticas y citomegalovirus.

- Si el primer nivel diagnóstico no permite concluir la etiología de la hipoacusia o no hay indicios clínicos que permitan sospecharla, se debe buscar la etiología genética, de acuerdo con el algoritmo de la Figura I.

- Remitir al paciente a una consulta de consejo genético.

- Con la intención de minimizar los costes del proceso, el primer paso recomendado es analizar la presencia de mutaciones en el gen GJB2 y de deleciones en GJB6. 
- Si no es posible identificar la causa de la sordera tras el análisis de estos genes, el siguiente paso debe ser la secuenciación de un panel de genes.

- Ofrecer al paciente y a sus familiares, la secuenciación de su exoma, destinado a identificar nuevos genes implicados en hipoacusias hereditarias, en los casos en los que, tras el adecuado proceso diagnóstico, no se ha identificado una causa de la sordera.

- No olvidar que un resultado negativo sólo indica que no se ha detectado una mutación en los genes analizados, pero no excluye la posibilidad de que la causa de la sordera sea genética.

- Se debe investigar en la historia del paciente la existencia de estudios previos por PCR positivos para el CMV en las tres primeras semanas de vida, lo que definiría la presencia de infección congénita.

- Se puede aprovechar la extracción sanguínea del estudio genético para la realización del estudio de la infección por CMV por PCR, en el caso de que éste no se haya podido determinar con anterioridad, siendo conscientes de que a partir de las 2-3 semanas de vida un resultado positivo a la presencia del virus tiene un valor para el diagnóstico de la infección congénita incierto.

- En casos de detección positiva, el estudio de la infección congénita debida a CMV se debería completar con la realización de PCR en muestras biológicas de las tres primeras semanas de vida almacenadas o en la muestra de sangre seca de la prueba de metabolopatías del recién nacido, en el caso de que estén disponibles. En casos así confirmados se debe valorar la utilidad de iniciar tratamiento con Valganciclovir.

- Si la confirmación de la infección congénita no fuera posible, el diagnóstico será de presunción y se basará en signos clínicos compatibles añadidos (problemas oculares, cerebrales, hematológicos...) a juicio del facultativo, que decidirá la actitud a seguir.

- Hacer el seguimiento de los niños infectados por CMV de forma congénita, al menos durante 6 años, con revisiones más frecuentes a los más afectados, dado que la sordera por CMV congénito, que se presenta tanto en niños sintomáticos, como asintomáticos, es fluctuante y con frecuencia postnatal.

- Tercer nivel diagnóstico. Pruebas de imagen.

- Tanto la TC como la RM son métodos adecuados y, en distintas situaciones, complementarios para el diagnóstico etiológico de las hipoacusias infantiles.

- Considerar la técnica que conlleve la mínima radiación para el paciente a la hora de elegir el tipo de prueba a aplicar en el proceso diagnóstico.

- Tener en cuenta la edad del paciente y el momento más idóneo para la realización de las pruebas. En la patología malformativa del oído externo y del oído medio, la técnica de elección es la TC. Es aconsejable esperar a los 3 años de edad siempre que no se necesite por alguna otra causa. Es mejor utilizar la TC de tipo Cone Beam CT, dado que es la que emite la mínima radiación y es muy eficiente para el diagnóstico.

- La RM es la técnica de elección en las malformaciones del oído interno, CAI y cerebro. Teniendo en cuenta que las lesiones del oído interno son la causa más frecuente de hipoacusia neurosensorial infantil, la RM debe ser el primer estudio de imagen.

- Cuarto nivel diagnóstico. Pruebas de laboratorio y otras pruebas.

- Valorar la determinación de hormonas tiroideas, análisis de orina u otras 
determinaciones analíticas orientadas a la detección de síndromes concretos, según sospecha clínica.

- Valorar la realización de ECG en aquellos niños sordos con síncopes u otras manifestaciones sugestivas de cardiopatía.
- Exploración oftalmológica.

- Siempre es necesaria la exploración oftalmológica complementaria, que puede además orientar hacia infecciones concretas o síndromes asociados a sordera. 


\section{Referencias bibliográficas}

Alarcón, A. y Baquero-Artigao, F. (20II): "Revisión y recomendaciones sobre la prevención, diagnóstico y tratamiento de la infección posnatal por citomegalovirus". Anales de Pediatría, 74: 52.er-52.er3.

Alford, R.L. et al. (20I4): “ACMG Working Group on Update of Genetics Evaluation Guidelines for the Etiologic Diagnosis of Congenital Hearing Loss; Professional Practice and Guidelines Committee. American College of Medical Genetics and Genomics guideline for the clinical evaluation and etiologic diagnosis of hearing loss". Genet Med, I6: 347-355.

American Academy of Pediatrics et al. (2006): "Guidelines for Monitoring and Management of Pediatric Patients During and After Sedation for Diagnostic and Therapeutic Procedures". Pediatrics, I I 8 (6): 2587-2602. Reaffirmed March 20II.

Atik, T. et al. (2015): “M. Whole-exome sequencing and its impact in hereditary hearing loss". Genet Res (Camb), 97: e4.

Badia, J. et al. (20I4): "Infecciones congénitas”. Pediatr Integral, I 8: 356-366.

Barkai, G. et al. (20I4): "Universal neonatal cytomegalovirus screening using saliva - report of clinical experience". J Clin Virol, 6o: $36 \mathrm{I}-366$.

Behar, D.M. et al. (2014): "The many faces of sensorineural hearing loss: one founder and two novel mutations affecting one family of mixed Jewish ancestry". Genet Test Mol Biomarkers, I 8: I23-I26.

Bockmühl, U. et al. (200I): "Visualization of inner ear displasias in patients with sensorineural hearing loss”. Acta Radiológica, 42: 574-58I.

Boppana, S.B. et al. (2010): "Dried blood spot realtime polymerase chain reaction assays to screen newborns for congenital cytomegalovirus infection". JAMA, 303: I375-I382.

Botet, F. et al. (2015): "Cribado universal de infección por citomegalovirus en prematuros de menos de I.500 g". Anales de Pediatría, $83: 69$.

Botet, F. et al. (20I4): "Cribado universal de infección por citomegalovirus en prematuros de menos de I.500 g". Anales de Pediatría, 8I: 256.eI-4.

Brenner, D.J. et al. (200I): "Estimated Risk of radiation Induced Fatal Cancer from Pediatric CT AJR". American Journal of Roentgenology, I76 (2): 289-296.

Brownstein, Z. et al. (20I I): "Targeted genomic capture and massively parallel sequencing to identify genes for hereditary hearing loss in Middle Eastern families". Genome Biol., I2: R89.

Cabanillas, R. y Cadiñanos, J. (20I2): "Hipoacusias hereditarias: asesoramiento genético". Acta Otorrinolaringol Esp., 63: 218-229

Cabanillas, R. et al. (20I I): "Nestor-Guillermo progeria syndrome: a novel premature aging condition with early onset and chronic development caused by BANFi mutations”. Am J Med Genet A.; I 5 A: 2617-2625.

Cannon, M.J. et al. (20I4): "Universal newborn screening for congenital CMV infection: what is the evidence of potential benefit?". Rev Med Virol, 24: 29I-307.

Cardoso, E.S. et al. (201 5): "The use of saliva as a practical and feasible alternative to urine in large-scale screening for congenital cytomegalovirus infection increases inclusion and detection rates". Rev. Soc. Bras. Med. Trop, 48: 206-207.

Casselman, J.W. et al. (I996): “Inner ear malformations in patients with sensorineural hearing loss: detection with gradient-echo (3DFT-CISS) MRI”. Neuroradiology; 38 (3): 278-286.

del Castillo, F.J. et al. (2005): “A novel deletion involving the connexin-30 gene, del (GJB6- 
$\left.\mathrm{d}_{1} 3 \mathrm{SI} 854\right)$, found in trans with mutations in the GJB2 gene (connexin-26) in subjects with DFNBI non-syndromic hearing impairment”. J Med Genet, 42: 588-594.

Chiang, C.E. (2004): "Congenital and acquired long QT syndrome. Current concepts and management”. Cardiol Rev., I 2: 222-234.

Choi, B.Y. et al. (2013): "Diagnostic application of targeted resequencing for familial nonsyndromic hearing loss". PLoS One., 8: e68692.

Choi, B.Y. et al. (2009): "Detection of cytomegalovirus DNA in dried blood spots of Minnesota infants who do not pass newborn hearing screening". Pediatr Infect Dis J, 28: $1095-1098$.

Cohen, B.E. et al. (20I4): "Viral causes of hearing loss: a review for hearing health professionals". Trends Hear, I8: I-I7.

Crotti et al. (2008): "Congenital long QT syndrome". Orphanet Journal of Rare Diseases, 3: I 8 .

Çelikel, E. et al. (201 5): "Evaluation of 98 immunocompetent children with cytomegalovirus infection: importance of neurodevelopmental follow-up". Eur J Pediatr., I74 (8): IIOI-IIO7.

Dahle, A.J. y McCollister, F.P. (I988): "Audiological findings in children with neonatal herpes”. Ear Hear, 9: 256-258.

De Vries, J.J. et al. (2013): "Cytomegalovirus DNA detection in dried blood spots and perilymphatic fluids from pediatric and adult cochlear implant recipients with prelingual deafness". J Clin Virol, 56: I I3-I I7.

Declau, F. et al. (2008): "Etiologic and audiologic evaluations after universal neonatal hearing screening: analysis of 170 referred neonates”. Pediatrics, I21: III9-II 26.

Deklerck, A.N. et al. (2015): "Etiological approach in patients with unidentified hearing loss". Int J Pediatr Otorhinolaryngol., 79: 216-222.

Demmler-Harrison, G. (20I5): Congenital cytomegalovirus infection: Clinical features and diagnosis (en línea). <http://www.uptodate. com/contents/congenital-cytomegalovirusinfection-clinicalfeatures-and-diagnosis $>$, acceso 7 de julio de 2015 .

Dyer J.J. et al. (1988): “Teratogenic hearing loss: a clinical perspective". Am J Otol., I9: 67I-678.

Escosa-García, L. et al. (201 5): "Cribado de citomegalovirus en prematuros menores de I.500 g. Comité Científico del Registro Estatal de Infección Congénita por Citomegalovirus”. An Pediatr., 83: 70-7I.

Estivill, X. et al. (1998): "Connexin-26 mutations in sporadic and inherited sensorineural deafness". Lancet., 35 I: 394-398.

Gallo-Terán, J. et al. (2005): "Prevalence of the 35 delG mutation in the GJB2 gene, del (GJB6$\mathrm{D}_{13} \mathrm{~S}_{1} 830$ ) in the GJB6 gene, Q829X in the OTOF gene and AI $555 \mathrm{G}$ in the mitochondrial I $2 \mathrm{~S}$ rRNA gene in subjects with non-syndromic sensorineural hearing impairment of congenital/ childhood onset”. Acta Otorrinolaringol Esp., 56: $463-468$.

Goderis, J. et al. (2OI4): "Hearing loss and congenital CMV infection: a systematic review”. Pediatrics, I34: 972-982.

Green, R.C. et al. (2013): “ACMG recommendations for reporting of incidental findings in clinical exome and genome sequencing”. Genet Med., I 5: 565-574.

$\mathrm{Gu}$, X. et al. (2OI3): "Genetic testing for sporadic hearing loss using targeted massively parallel sequencing identifies ro novel mutations". Clin Genet., 87: 588-593.

Gunkel, J. et al. (20I4): "Urine is superior to saliva when screening for postnatal CMV infections in preterm infants". J Clin Virol, 6I: 6I-64.

Jacobson, S.G. et al. (20I 5): "Improvement and decline in vision with gene therapy in childhood blindness". N Engl J Med., 372: I920-1926.

Jamuar, S.S. y Tan, E.C. (20I 5): “Clinical application of next-generation sequencing for Mendelian diseases”. Hum Genomics., 9: Iо.

Ji, H. et al. (2OI4): "Combined examination of sequence and copy number variations in human 
deafness genes improves diagnosis for cases of genetic deafness”. BMC Ear Nose Throat Disord., I4: 9 .

Joint Committee on Infant Hearing (2007): "Year 2007 position statement: principles and guidelines for early hearing detection and intervention programs". Pediatrics, I 20: 898$92 \mathrm{I}$.

Kadambari, S. et al. (2015): "Evaluating the feasibility of integrating salivary testing for congenital CMV into the Newborn Hearing Screening Programme in the UK". Eur J Pediatr., I74 (8): III7-II2I.

Kadambari, S. et al. (2013): "Clinically targeted screening for congenital CMV - potential for integration into the National Hearing Screening Programme”. Acta Pediatr; I02: 928-933.

Karltorp, E. et al. (20I2): “Congenital cytomegalovirus infection - a common cause of hearing loss of unknown aetiology". Acta Pediatr, IоI: e357-62.

Kenneson, A. et al. (2002): "GJB2 (connexin 26) variants and nonsyndromic sensorineural hearing loss: a HuGE review". Genet Med., 4: 258-274.

Kimberlin, D.W. et al. (2OI 5): "Valganciclovir for symptomatic congenital cytomegalovirus disease". N Engl J Med, 372: 933-943.

Kochhar, A. et al. (2007): "Clinical aspects of hereditary hearing loss”. Genet Med., 9: 393408 .

Kohda, C. et al. (20I4): “A simple smart amplification assay for the rapid detection of human cytomegalovirus in the urine of neonates". J Virol Methods, 208: I60-165.

Koontz, D. et al. (2015): "Evaluation of DNA extraction methods for the detection of Cytomegalovirus in dried blood spots". J Clin Virol., 66: 95-99.

Laury et al. (2009): "Etiology of unilateral neural hearing loss in children". International Journal of Pediatric Otorhinolaringology, 73: 4I7-427.

Lee, C.I. et al. (2004): “Diagnostic CT Scans: Assessment of Patient, Physician, and
Radiologist Awareness of Radiation Dose and Possible Risks”. Radiology, 23 I: 393-398.

Lemmerling, M. y Foer, B. (eds.) (2015): “Temporal Bone Imaging”. Springer-Verlag Berlin Heidelberg.

Lim, B.G. et al. (2OI3): "Utility of genetic testing for the detection of late-onset hearing loss in neonates". Am J Audiol, 22: 209-2I 5.

Lin, J.W. et al. (20I I): "Comprehensive diagnostic battery for evaluating sensorineural hearing loss in children”. Otol Neurotol., 32: 259-264.

Lu, Y. et al. (20I4): "Resolving the genetic heterogeneity of prelingual hearing loss within one family: Performance comparison and application of two targeted next generation sequencing approaches". J Hum Genet., 59: 599-607.

MacLaren, R.E. et al. (2OI4): "Retinal gene therapy in patients with choroideremia: initial findings from a phase $\mathrm{x} / 2$ clinical trial”. Lancet., 383: I I 29-I I 37 .

Madden, C. et al. (2007): "The influence of mutations in the SLC26A4 gene on the temporal bone in a population with enlarged vestibular aqueduct". Arch Otolaryngol Head Neck Surg., I33: I62-I68.

Mafong, D.D. et al. (2002): "Use of laboratory evaluation and radiologic imaging in the diagnostic evaluation of children with sensorineural hearing loss". Laryngoscope, I I2: I-7.

Muller, U. y Barr-Gillespie, P.G. (20I 5 ): “New treatment options for hearing loss". Nat Rev Drug Discov., I4: 346-365.

Núñez, F. et al. (201 5): "Recomendaciones CODEPEH 20I4", Revista Española de Discapacidad, 3 (I): I63-I86.

Nuñez-Ramos, R. et al. (20I3): "Early diagnosis of congenital cytomegalovirus infection: lost opportunities". Enferm Infecc Microbiol Clin, 3I: 93-96.

Palmer, C.G. et al. (2009): “A prospective, longitudinal study of the impact of GJB2/GJB6 genetic testing on the beliefs and attitudes of 
parents of deaf and hard-of-hearing infants". Am J Med Genet A., I49A: I I69-II82.

Park, A.H. et al. (2014): “A diagnostic paradigm including cytomegalovirus testing for idiopathic pediatric sensorineural hearing loss".

Laryngoscope, I 24: 2624-2629.

Preciado, D.A. et al. (2005): "Improved diagnostic effectiveness with a sequential diagnostic paradigm in idiopathic pediatric sensorineural hearing loss”. Otol Neurotol, 26: 6I0-6I 5.

Pickett, B.P. y Ahlstrom, K. (I999) “Clinical evaluation of the hearing-impaired infant”. Otolaryngol Clin North Am., 32: IOI9-IO35.

Rangan, S. et al. (20I2): "Deafness in children: a national survey of aetiological investigations". BMJ Open, 2: eooII74.

Rehm, H.L. (20I3). "Disease-targeted sequencing: a cornerstone in the clinic". Nat Rev Genet., I4: 295-300.

Rehm, H.L. et al. (20I3): “ACMG clinical laboratory standards for next-generation sequencing”. Genet Med., I 5: 733-747.

Robin, N.H. et al. (201 5): "The use of genetic testing in the evaluation of hearing impairment in a child”. Curr Opin Pediatr., I7: 709-7 I 2.

Ross, S. et al. (2015): "Urine Collection Method for the Diagnosis of Congenital Cytomegalovirus Infection". Pediatr Infect Dis J., 34: 903-905.

Sando, I. et al. (I998): "Frequency and localization of congenital anomalies of the middle and inner ears: a human temporal bone histopathologicalstudy". Int J Pediatric Otorhinolaryngol., I6 (I): I-22.

Sanger, F. y Coulson, A.R. (I975): “A rapid method for determining sequences in DNA by primed synthesis with DNA polymerase". J Mol Biol., 94: 44I-448.

Schimmenti, L.A. et al. (20I I): "Evaluation of newborn screening bloodspot-based genetic testing as second tier screen for bedside newborn hearing screening”. Genet Med, I3: I006-IOIO.

Schleiss, M.R. (20I3): “Developing a Vaccine against Congenital Cytomegalovirus (CMV)
Infection: What Have We Learned from Animal Models? Where Should We Go Next?". Future Virol, 8: II6I-II 82.

Schrauwen, I. et al. (2013): “A sensitive and specific diagnostic test for hearing loss using a microdroplet PCR-based approach and next generation sequencing". Am J Med Genet A., I6IA: I45-I 52 .

Shearer, A.E. y Smith, R.J. (2OI 5): "Massively Parallel Sequencing for Genetic Diagnosis of Hearing Loss: The New Standard of Care". Otolaryngol Head Neck Surg., I 53: I75-I 82.

Shearer, A.E. et al. (20I4): "Copy number variants are a common cause of non-syndromic hearing loss”. Genome Med., 6: 37 .

Shearer, A.E. et al. (2013): "Advancing genetic testing for deafness with genomic technology". J Med Genet., 50: 627-634.

Shearer, A.E. et al. (2010): "Comprehensive genetic testing for hereditary hearing loss using massively parallel sequencing". Proc Natl Acad Sci U S A., I07 (49): 21.104-2I.I09.

Singh, D. et al. (2015): "MR Evaluation of vestibulocochear Neuropathy". J Neuroimaging, I038-I430.

Smiechura, M. et al. (2014): "Congenital and acquired cytomegalovirus infection and hearing evaluation in children". Otolaryngol Pol, 68: 303-307.

Takemori, S. et al. (1976): "Thalidomideanomalies of theear". Arch Otolaryngol, I02: 425-427.

Teek, R. et al. (2013): "Hearing impairment in Estonia: an algorithm to investigate genetic causes in pediatric patients". Adv Med Sci, 58 : 419-428.

Tekin, D. et al. (20I4): "Comprehensive genetic testing can save lives in hereditary hearing loss". Clin Genet., 87: 190-I9I.

Thomas, K.E. et al. (2006): “Assessment of radiation dose awareness among pediatricians". Pediatr Radiol., 36: 823-832.

Toumpas, C.J. et al. (2OI4): “Congenital cytomegalovirus infection is a significant cause of moderate to profound sensorineural hearing 
loss in Queensland children". Journal of

Paediatrics and Child Health, 5I: 54 I-544.

Trinidad, G. et al. (2010): "Recomendaciones de la Comisión para la Detección Precoz de la Hipoacusia (CODEPEH) para 2010". Acta Otorrinolaringol. Esp, 6r: 69-77.

Valvassori, G.E. et al. (I969): "Inner ear anomalies: clinical and histopathological considerations". Ann Otol Rhinol Laryngol., (5): 929-938.

Vona, B. et al. (201 5): "Non-syndromic hearing loss gene identification: A brief history and glimpse into the future”. Mol Cell Probes, 29 (5): $260-270$

Vona, B. et al. (20I4): "Targeted nextgeneration sequencing of deafness genes in hearingimpaired individuals uncovers informative mutations". Genet Med., I6: 945953.

Wang, D. y Fu, T.M. (20I4): "Progress on human cytomegalovirus vaccines for prevention of congenital infection and disease". Curr Opin Virol, 6: 13-23.
Wei, X. et al. (20I2): "Next-generation sequencing identifies a novel compound heterozygous mutation in $\mathrm{MYO}_{7} \mathrm{~A}$ in a Chinese patient with Usher Syndrome IB". Clin Chim Acta., 4I3: I 866-I 87I.

Williams, E.J. et al. (2OI 5): "First estimates of the potential cost and cost saving of protecting childhood hearing from damage caused by congenital CMV infection”. Arch Dis Child Fetal Neonatal, I00 (6): F50I-F506.

Williams, E.J. et al. (20I4): "Feasibility and acceptability of targeted screening for congenital CMV-related hearing loss”. Arch Dis Child Fetal Neonatal, 99: F230-F236.

Young, T.L. et al. (200I): "Nom - syndromic progressive hearing loss $\mathrm{DFNA}_{3} 8$ is caused by heterozygous missense mutation in the Wolfram Syndrome gene WFS I". Hum Mol Genet, Iо: 2509-25I4.

Yu, Q. et al. (20I4): "Virally expressed connexin26 restores gap junction function in the cochlea of conditional Gjb2 knockout mice”. Gene Ther., 2I: 7I-8O. 